\title{
Relationship between Oxygenation in Inactive Biceps Brachii Muscle and Hyperventilation during Leg Cycling
}

\author{
H. OGATA, T. ARIMITSU, R. MATSUURA, T. YUNOKI, M. HORIUCHI ${ }^{1}$, \\ T. YANO
}

Laboratory of Exercise Physiology, Graduate School of Education, Hokkaido University, Kita-ku, Sapporo City, Japan, ' Department of Human Care Studies, Asai Gakuen University, Ebetsu City, Japan

Received October 26, 2006

Accepted January 19, 2006

On-line available February 23, 2006

\begin{abstract}
Summary
Inactive forearm muscle oxygenation has been reported to begin decreasing from the respiratory compensation point (RCP) during ramp leg cycling. From the RCP, hyperventilation occurs with a decrease in arterial $\mathrm{CO}_{2}$ pressure $\left(\mathrm{PaCO}_{2}\right)$. The aim of this study was to determine which of these two factors, hyperventilation or decrease in $\mathrm{PaCO}_{2}$, is related to a decrease in inactive biceps brachii muscle oxygenation during leg cycling. Each subject $(n=7)$ performed a 6-min two-step leg cycling. The exercise intensity in the first step $(3 \mathrm{~min})$ was halfway between the ventilatory threshold and RCP (170 \pm 21 watts), while that in the second step $(3 \mathrm{~min})$ was halfway between the RCP and peak oxygen uptake ( $240 \pm 28$ watts). The amount of hyperventilation and $\mathrm{PaCO}_{2}$ were calculated from gas parameters. The average cross correlation function in seven subjects between inactive muscle oxygenation and amount of hyperventilation showed a negative peak at the time shift of zero $(r=-0.72, p<0.001)$, while that between inactive muscle oxygenation and calculated $\mathrm{PaCO}_{2}$ showed no peak near the time shift of zero. Thus, we concluded that decrease in oxygenation in inactive arm muscle is closely coupled with increase in the amount of hyperventilation.
\end{abstract}

\section{Key words}

Hyperventilation $\bullet$ Inactive muscle $\bullet$ Oxygen supply $\bullet$ Arterial carbon dioxide pressure

\section{Introduction}

We have recently examined oxygenation kinetics in inactive forearm muscle during ramp leg cycling (Ogata et al. 2004). Change in oxygenation in inactive muscle was used as an index of change in oxygen supply, since oxygenation is influenced by oxygen consumption and oxygen supply and since oxygen consumption is assumed to be almost constant in inactive muscle (Ogata et al. 2002, Yano et al. 2005). We found that oxygenation in inactive forearm muscle began to decrease from the respiratory compensation point (RCP) during ramp leg cycling. From the RCP, the rate of increase in minute ventilation (VE) against power output begins to rise abruptly. The hyperventilation is accompanied by a decrease in arterial $\mathrm{CO}_{2}$ pressure. Hypocapnia is known to decrease cerebral oxygenation (Grote et al. 1981, Hampson and Piantadosi 1990), but the results for 
skeletal muscle are contradictory (Gustafsson et al. 1993, Hampson and Piantadosi 1990). Thus, we hypothesized that hyperventilation per se may be related to a decrease in oxygenation in inactive arm muscle during leg cycling. The aim of the present study was to determine which factor, hyperventilation or decrease in $\mathrm{PaCO}_{2}$, is related to a decrease in oxygenation in inactive biceps brachii muscle during leg cycling. In the present study, the amount of hyperventilation was extracted from the actual $\dot{\mathrm{V} E}$ using the method of Koyal et al. (1976), and the change in $\mathrm{PaCO}_{2}$ was predicted from the change in endtidal $\mathrm{CO}_{2}$ pressure using the method of Jones et al. (1979).

\section{Methods}

\section{Subjects}

Seven healthy male subjects participated in this study. They had no cardiovascular risk factors, were not taking any medication, and were not engaged in any formal exercise-training program. Mean values $( \pm \mathrm{SD})$ of age, height and weight of the subjects were $24 \pm 2$ years, $175 \pm 7 \mathrm{~cm}$ and $70 \pm 7 \mathrm{~kg}$, respectively. Voluntary consent for the participation in this study was obtained from all subjects after informing them of the purpose of the experiment, the procedure, and possible risks. This study was approved by the local ethics committee.

\section{Experimental protocol}

Ramp leg cycling was performed using a bicycle ergometer (Ergometer 232CXL, Combi, Tokyo, Japan) in an upright position to determine exercise intensities at the ventilatory threshold (VT), RCP and peak oxygen uptake $\left(\mathrm{VO}_{2 \text { peak }}\right)$. Before the experiment, each subject sat on the saddle with his toes on the pedals. Then the seat height was adjusted so that there was a slight bend in the knee joint when the foot pedal was at its lowest point. At the start of the experiment, subjects rested for $5 \mathrm{~min}$ and then the work load was increased by 20 Watts every minute until exhaustion. $\mathrm{VO}_{2 \text { peak }}$ was defined as the peak value obtained in this test.

On separate days after completion of ramp exercise, each subject performed two-step incremental leg cycling $\left(\mathrm{LC}_{\mathrm{inc}}\right)$. Before the exercise, each subject rested for $5 \mathrm{~min}$ and then performed a 6-min exercise. After the excercise, each subject recovered for $5 \mathrm{~min}$. The intensity of exercise in the first step ( $3 \mathrm{~min}$ ) was halfway between VT and RCP, while that in the second step ( $3 \mathrm{~min}$ ) was halfway between $\mathrm{RCP}$ and $\dot{\mathrm{VO}}_{2 \text { peak. }}$ The reason for using this protocol is as follows. Hyperventilation occurs during exercise above the VT. The level of hyperventilation is smaller than that observed from the RCP. This characteristic is useful if the magnitude of decrease in muscle oxygenation is compared to the magnitude of increase in the amount of hyperventilation. Each subject also performed two-step decremental exercise $\left(\mathrm{LC}_{\mathrm{dec}}\right)$. The intensity of exercise in the first step (3 min) was halfway between RCP and $\dot{\mathrm{VO}}_{2 \text { peak, }}$, while that in the second step ( $3 \mathrm{~min}$ ) was halfway between VT and RCP. In this exercise, the pattern of change in hyperventilation dissociates completely from that in predicted $\mathrm{PaCO}_{2}$ as shown in Figure 1. This characteristic is useful to examine the relationship to change in inactive muscle oxygenation. These two experiments were performed on different days and in random order.

All exercises, including ramp and two-step exercises, were performed at $60 \mathrm{rpm}$. The subjects were asked to keep their arms resting as much as possible on a table adjusted to the height of heart level throughout the rest, exercise and recovery periods.

\section{Measurements}

Change in muscle oxygenation was determined using a near-infrared spectrometer (NIRS, HEO200N, Omron, Tokyo, Japan) as described in detail elsewhere (Ogata et al. 2004). It is known that both hemoglobin $(\mathrm{Hb})$ and myoglobin $(\mathrm{Mb})$ absorb NIRS radiation. There are conflicting data regarding the influence of myoglobin on the NIRS signal (Mancini et al. 1994, Tran et al. 1999). It is considered that NIRS oxygenation values represent volume-averaged values in the portion of tissue under consideration, i.e. coming from $\mathrm{Hb}$ and $\mathrm{Mb}$ (Grassi et al. 2003). NIRS provides separate measures of changes in concentrations of oxygenated $\mathrm{Hb}+\mathrm{Mb}($ oxyHb/Mb) and deoxygenated $\mathrm{Hb}+\mathrm{Mb}(\operatorname{deoxyHb} / \mathrm{Mb})$. In the present study, $\mathrm{oxyHb} / \mathrm{Mb}$ was used as a measure of muscle oxygenation.

Based on the method used in previous investigations (Hamaoka et al. 1996, Higuchi et al. 2002), change in $о x y \mathrm{Hb} / \mathrm{Mb}$ was normalized using the arterial occlusion method, and the relative change in oxyHb/Mb (\%) was estimated in the present study. The minimum oxyHb/Mb level during arterial occlusion was regarded as $0 \%$, and the $0 x y \mathrm{Hb} / \mathrm{Mb}$ level at rest was regarded as $100 \%$. The resting level was regarded as an average of data between the first and the fourth minutes during a 5 -min resting period.

In the two-step exercise tests, the NIRS probe 
A

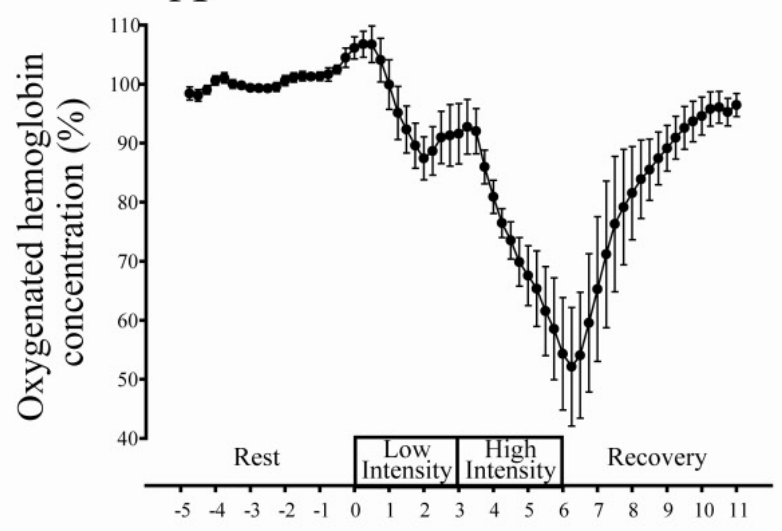

C

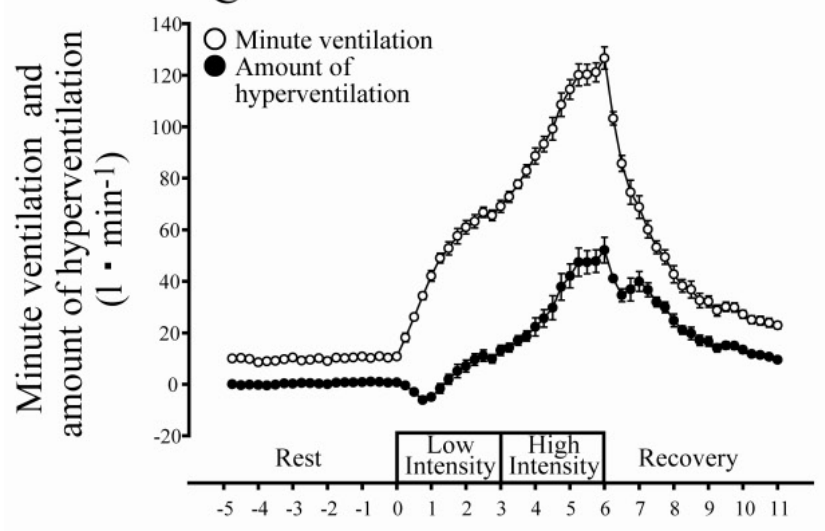

E

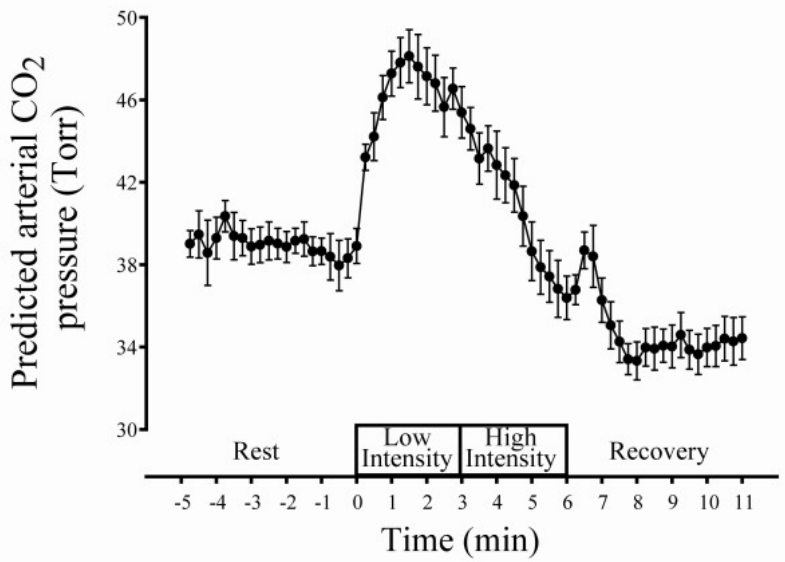

B

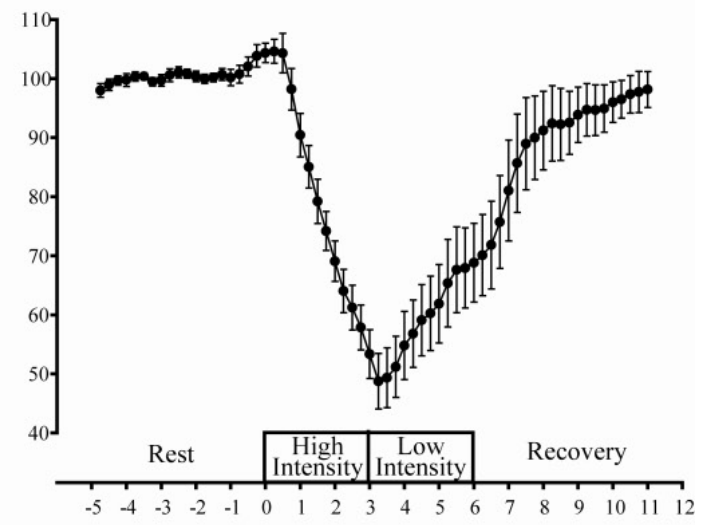

D

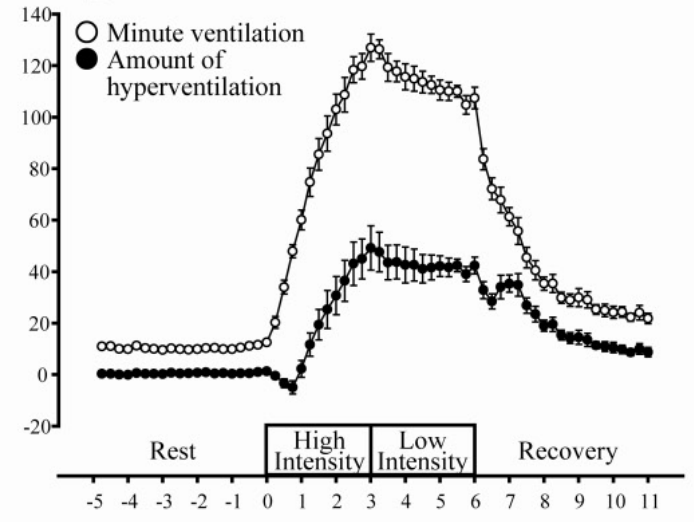

F

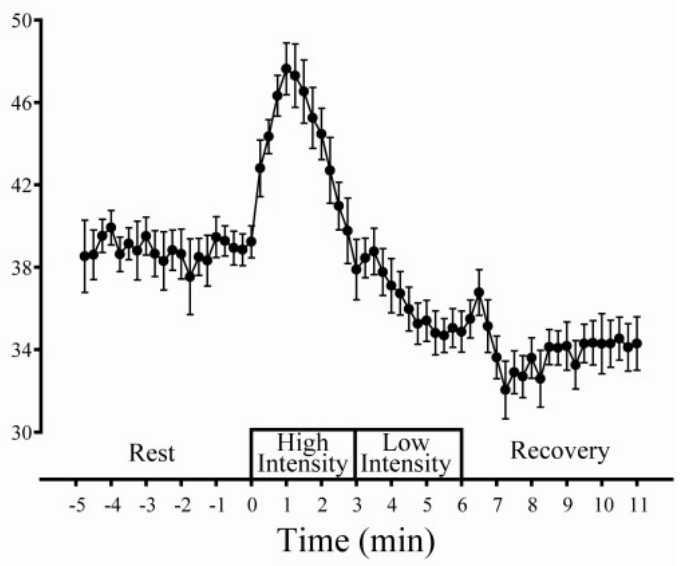

Fig. 1. Changes in oxygenated hemoglobin/myoglobin concentration in inactive biceps brachii muscle (top), minute ventilation and amount of hyperventilation (middle), and predicted arterial $\mathrm{CO}_{2}$ pressure (bottom) during two-step incremental and decremental exercises (left and right, respectively). In the middle panels, an open circle $(\bigcirc)$ denotes minute ventilation, while a filled circle $(\mathbf{O})$ denotes amount of hyperventilation. The amount of hyperventilation was defined as the difference between actual minute ventilation (VE) and VE estimated using the oxygen uptake-VE relationship below the ventilatory threshold during ramp leg cycling. PaCO 2 pre was calculated from end-tidal $\mathrm{CO}_{2}$ pressure. During two-step incremental exercise, the intensity of exercise in the first step (3 min) was halfway between the ventilatory threshold (VT) and respiratory compensation point (RCP) recorded during ramp leg cycling, while that in the second step $(3 \mathrm{~min})$ was halfway between the $\mathrm{RCP}$ and maximal oxygen uptake $\left(\mathrm{VO}_{2 \text { peak }}\right)$. During .two-step decremental exercise, on the other hand, the intensity of exercise in the first step $(3 \mathrm{~min})$ was halfway between the RCP and $\mathrm{VO}_{2 \text { peak, }}$ while that in the second step ( $3 \mathrm{~min}$ ) was halfway between the VT and RCP. Values are means \pm S.E.M. $(n=7)$. 
was fixed over the belly of the biceps brachii muscle of the right forearm of each subject and NIRS signals were measured during rest, exercise, and recovery periods with a sampling time of $5 \mathrm{~s}$. The averages of these data were calculated for each 15-s interval and these averages were used for statistical analysis.

Data on $\dot{\mathrm{VE}}$, oxygen uptake $\left(\dot{\mathrm{VO}}_{2}\right)$, carbon dioxide $\left(\dot{\mathrm{VCO}}_{2}\right)$, end-tidal $\mathrm{O}_{2}$ pressure $\left(\mathrm{PETO}_{2}\right)$ and endtidal $\mathrm{CO}_{2}$ pressure $\left(\mathrm{PETCO}_{2}\right)$ were obtained breath-bybreath using a respiratory gas analyzer (AE-280S, Minato Medical Science, Osaka, Japan). VE was measured by a hot-wire flow meter, and the flow meter was calibrated with a syringe of known volume $(2.01) . \mathrm{O}_{2}$ and $\mathrm{CO}_{2}$ concentrations were measured by a zirconium sensor and infrared absorption analyzer, respectively. The gas analyzer was calibrated by known standard gas $\left(\mathrm{O}_{2}\right.$ $15.17 \%, \mathrm{CO}_{2} 4.92 \%$ ). Heart rate (HR) was recorded using a heart rate monitor installed in the respiratory gas analyzer. These data were measured continuously during rest, exercise, and recovery periods. The averages of these data were calculated for each 15 -s interval and these averages were used for statistical analysis.

Blood samples (each $25 \mu \mathrm{l}$ ) were taken from a fingertip and immediately analyzed for blood lactate concentration ([ $\left.\left.\mathrm{La}^{-}\right]\right)$using a blood lactate analyzer (1500 Sport, YSI, Ohio, USA). The analyzer was calibrated by known standard solution $(5 \mathrm{mmol})$. In the two-step exercise tests, blood samples were collected at rest and at the 3 rd and 6 th min of exercise.

\section{Data analysis}

VT was determined using the following criteria: i) an increase in $\dot{\mathrm{VE}}$ relative to $\mathrm{VO}_{2}$, ii) an increase in $\mathrm{VCO}_{2}$ relative to $\mathrm{VO}_{2}$, iii) an increase in $\mathrm{PETO}_{2}$ without a decrease in $\mathrm{PETCO}_{2}$, and biv) an increase in $\mathrm{VE} / \dot{\mathrm{VO}}_{2}$ without an increase in $\mathrm{VE} / \mathrm{VCO}_{2}$ (Scheuermann and Kowalchuk 1998). The respiratory compensation point (RCP) was determined as the point at which $\mathrm{VE} / \mathrm{VCO}_{2}$ began to increase and at which $\mathrm{PETCO}_{2}$ began to decrease following the isocapnic buffering phase (Oshima et al. 1997, Scheuermann and Kowalchuk 1998, Takano 2000).

Based on the method of Koyal et al. (1976), the amount of hyperventilation $\left(\dot{\mathrm{VE}}_{\mathrm{hyper}}\right)$ during each twostep exercise was calculated in the following manner. A linear regression line of $\dot{\mathrm{VE}}$ against $\dot{\mathrm{VO}}_{2}$ was made using data below the $\mathrm{VT}$ recorded during ramp leg cycling. $\mathrm{VO}_{2}$ obtained during each two-step exercise was substituted into the expression of the linear regression line and predicted VE was calculated. The difference between predicted $\dot{\mathrm{VE}}$ and actual VE obtained during two-step exercise was defined as $\dot{\mathrm{V}} \mathrm{E}_{\text {hyper }}$.

Arterial $\mathrm{CO}_{2}$ pressure $\left(\mathrm{PaCO}_{2}\right)$ was predicted from $\mathrm{PETCO}_{2}$ using the following equation (Jones et al. 1979): predicted $\mathrm{PaCO}_{2}\left(\mathrm{PaCO}_{2 p r e}\right)=5.5+$ $0.90 \cdot \mathrm{PETCO}_{2}-0.0021 \cdot$ tidal volume, where $\mathrm{PaCO}_{2 \text { pre }}$ and $\mathrm{PETCO}_{2}$ are in Torr and tidal volume is in $\mathrm{ml}$.

Cross-correlation was applied to the following time series: 1) oxyHb/Mb and $\dot{\mathrm{VE}}_{\text {hyper }}$ in $\mathrm{LC}_{\text {inc }}$, 2) oxyHb/Mb and $\mathrm{PaCO}_{2 \text { pre }}$ in $\left.\mathrm{LC}_{\text {inc }}, 3\right)$ oxyHb/Mb and $\mathrm{VE}$ hyper in $\mathrm{LC}_{\text {dec }}$, and 4) oxyHb/Mb and $\mathrm{PaCO}_{2 \text { pre }}$ in $\mathrm{LC}_{\mathrm{dec}}$. To evaluate the cross correlation coefficient and time shift between two time series, the cross correlation function (CCF) was applied. We determined the negative peak of the $\mathrm{CCF}$ between oxyHb/Mb and $\dot{\mathrm{VE}}_{\text {hyper }}$ and the positive peak of the $\mathrm{CCF}$ between oxyHb/Mb and $\mathrm{PaCO}_{2 \text { pre. }}$ Time shifts from zero to the time point at which the peaks were observed were also determined.

Paired student's t-test was used for comparison of the values at the $3 \mathrm{rd}$ and the 6th minutes of exercise and for comparison of the values at the $3 \mathrm{rd} \min$ of $\mathrm{LC}_{\text {inc }}$ and the 6 th min of $\mathrm{LC}_{\mathrm{dec}}$. A value of $\mathrm{p}<0.05$ was regarded as statistically significant. All data are presented as means $\pm \mathrm{SE}$.

\section{Results}

The highest values of work rate at exhaustion and peak HR obtained during ramp leg cycling were $270 \pm 12$ Watts and $175 \pm 2 \mathrm{bpm}$, respectively. Table 1 shows the work rate, cardiorespiratory data measured at rest, VT, RCP and $\mathrm{VO}_{2}$ peak. The values of $\dot{\mathrm{VO}}_{2}$ at the VT and RCP were $50 \pm 2$ and $77 \pm 2 \%$ of $\dot{\mathrm{VO}}_{2}$ peak, respectively.

The work rates halfway between VT and RCP and halfway between RCP and $\mathrm{VO}_{2}$ peak were $170 \pm 7$ and $240 \pm 10$ Watts, respectively. These values corresponded to $63 \pm 1$ and $89 \pm 1 \%$ of peak work rate, respectively. Table 2 shows cardiorespiratory, $\left[\mathrm{La}^{-}\right]$and $\mathrm{oxyHb} / \mathrm{Mb}$ data recorded at rest, at the $3 \mathrm{rd}$ and the 6 th $\min$ of exercise, and at the 5th min of recovery. Values of $\mathrm{VO}_{2}$ recorded at the $3 \mathrm{rd}$ and 6 th $\mathrm{min}$ of $\mathrm{LC}_{\text {inc }}$ corresponded to $76 \pm 2$ and $103 \pm 1 \%$ of $\mathrm{VO}_{2}$ peak, respectively, while those recorded at the $3 \mathrm{rd}$ and the 6th minutes of $\mathrm{LC}_{\mathrm{dec}}$ corresponded to $98 \pm 2$ and $93 \pm 3 \%$ of $\dot{\mathrm{VO}}_{2 \text { peak }}$, respectively. The value of $\mathrm{VO}_{2}$ at the 6th min of $\mathrm{LC}_{\text {inc }}$ exceeded the value of $\dot{\mathrm{VO}}_{2 \text { peak }}$ recorded during ramp leg cycling. The reason for this is that $\mathrm{VO}_{2 \text { peak }}$ recorded 
Table 1. Averages of work rate, oxygen uptake $\left(\dot{\mathrm{VO}}_{2}\right)$, minute ventilation $(\dot{\mathrm{V} E})$ and heart rate $(\mathrm{HR})$ measured at rest and at the ventilatory threshold $(\mathrm{VT})$, respiratory compensation point (RCP) and peak oxygen uptake ( $\mathrm{V}_{2}{ }_{2 \text { peak}}$ ) during ramp leg cycling in seven subjects.

\begin{tabular}{|c|c|c|c|c|}
\hline & Rest & VT & RCP & $\dot{\mathrm{V}} \mathrm{O}_{2 \text { peak }}$ \\
\hline Work rate (Watts) & & $133 \pm 7$ & $207 \pm 11$ & $270 \pm 12$ \\
\hline $\mathrm{VO}_{2}\left(l \cdot \mathrm{min}^{-1}\right)$ & $0.26 \pm 0.01$ & $1.47 \pm 0.05$ & $2.24 \pm 0.08$ & $2.92 \pm 0.10$ \\
\hline$\dot{V} E\left(l . m^{-1}{ }^{-1}\right)$ & $9 \pm 1$ & $37 \pm 2$ & $66 \pm 2$ & $130 \pm 6$ \\
\hline$H R(b p m)$ & $63 \pm 2$ & $114 \pm 3$ & $150 \pm 5$ & $175 \pm 2$ \\
\hline
\end{tabular}

Values are means \pm S.E.M. $(n=7)$.

Table 2. Oxygen uptake $\left(\dot{\mathrm{VO}}_{2}\right)$, minute ventilation $(\dot{\mathrm{V} E})$, amount of hyperventilation $\left(\dot{\mathrm{V}} \mathrm{E}_{\text {hyper }}\right)$, predicted arterial $\mathrm{CO}_{2}$ pressure $\left(\mathrm{PaCO}_{2 \text { pre }}\right)$, heart rate (HR), oxygenated hemoglobin/myoglobin concentration in inactive biceps brachii muscle (oxyHb/Mb) and blood lactate concentration ([La] $)$ at rest, during exercise at the 3rd and 6th $\min$ (Ex3 and Ex6, respectively), and during recovery at the 5th min (Rec5) in two-step incremental and decremental exercise tests (upper and lower, respectively).

\begin{tabular}{|c|c|c|c|c|c|c|c|c|}
\hline & & $\begin{array}{l}\dot{\mathrm{VO}} \mathrm{O}_{2} \\
\left(1 . \mathrm{min}^{-1}\right)\end{array}$ & $\begin{array}{l}\text { VE } \\
\left(1 . \min ^{-1}\right)\end{array}$ & $\begin{array}{l}\dot{V E}_{\text {hyper }} \\
\left(1 . \text { min }^{-1}\right)\end{array}$ & $\begin{array}{l}\mathrm{PaCO}_{2 \text { pre }} \\
\text { (Torr) }\end{array}$ & $\begin{array}{l}\text { HR } \\
(\text { bpm) }\end{array}$ & $\begin{array}{l}\text { оxyHb/Mb } \\
(\%)\end{array}$ & $\begin{array}{l}{\left[\mathrm{La}^{-}\right]} \\
\left(\mathrm{mmol}^{-\mathrm{l}^{-1}}\right)\end{array}$ \\
\hline \multirow{4}{*}{$\begin{array}{l}\text { two-step } \\
\text { incremental } \\
\text { exercise }\end{array}$} & Rest & $0.26 \pm 0.01$ & $10 \pm 1$ & $0 \pm 1$ & $39 \pm 1$ & $66 \pm 3$ & $100 \pm 0$ & $1.04 \pm 0.08$ \\
\hline & Ex3 & $2.20 \pm 0.07$ & $69 \pm 2$ & $13 \pm 2$ & $45 \pm 1$ & $147 \pm 4$ & $92 \pm 5$ & $5.10 \pm 0.52$ \\
\hline & Ex6 & $2.99 \pm 0.09^{*}$ & $127 \pm 4^{*}$ & $52 \pm 5^{*}$ & $36 \pm 1 *$ & $175 \pm 2 *$ & $54 \pm 10^{*}$ & $9.34 \pm 0.86^{*}$ \\
\hline & $\operatorname{Rec} 5$ & $0.43 \pm 0.02$ & $23 \pm 1$ & $10 \pm 1$ & $34 \pm 1$ & $103 \pm 3$ & $96 \pm 2$ & \\
\hline \multirow{4}{*}{$\begin{array}{l}\text { two-step } \\
\text { decremental } \\
\text { exercise }\end{array}$} & Rest & $0.27 \pm 0.02$ & $10 \pm 1$ & $1 \pm 1$ & $39 \pm 1$ & $66 \pm 5$ & $100 \pm 0$ & $1.19 \pm 0.10$ \\
\hline & Ex3 & $2.87 \pm 0.12$ & $127 \pm 5$ & $49 \pm 9$ & $38 \pm 1$ & $168 \pm 3$ & $53 \pm 4$ & $8.37 \pm 0.73$ \\
\hline & Ex6 & $2.70 \pm 0.06^{\#}$ & $107 \pm 4^{* \#}$ & $42 \pm 3^{\#}$ & $35 \pm 1 *^{\#}$ & $163 \pm 3 *^{\#}$ & $69 \pm 7^{\#}$ & $12.42 \pm 0.86^{* \#}$ \\
\hline & $\operatorname{Rec} 5$ & $0.41 \pm 0.02$ & $22 \pm 2$ & $9 \pm 2$ & $34 \pm 1$ & $97 \pm 4$ & $98 \pm 3$ & \\
\hline
\end{tabular}

Values are means \pm S.E.M. $(n=7)$. The work rates in the first step (Ex3, halfway between the ventilatory threshold and respiratory compensation point) and second step (Ex6, halfway between the respiratory compensation point and peak oxygen uptake) of two-step incremental exercise are identical to those in the second step. (Ex6) and first step (Ex3) of two-step decremental exercise, respectively. $\mathrm{VE}_{\text {hyper }}$ was defined as the difference between actual $\mathrm{VE}$ and $\mathrm{VE}$ estimated using the $\mathrm{VO}_{2}-\mathrm{VE}$ relationship below the ventilatory threshold during ramp leg cycling. $\mathrm{PaCO}_{2 \text { pre }}$ was calculated from end-tidal $\mathrm{CO}_{2}$ pressure. *: significant difference from values at the 3rd min. \#: significant difference from values at the $3 \mathrm{rd}$ min of two-step incremental exercise.

during ramp leg cycling was submaximal as evidenced by peak HR (175 $\pm 2 \mathrm{bpm})$ attained during ramp leg cycling, the value of which is far below predicted peak HR (200 bpm).

Figures $1 \mathrm{~A}$ and $1 \mathrm{~B}$ show average changes in oxyHb/Mb in $\mathrm{LC}_{\text {inc }}$ and $\mathrm{LC}_{\text {dec }}$, respectively. oxyHb/Mb began to decrease about $30 \mathrm{~s}$ after the onset of exercise in both $\mathrm{LC}_{\mathrm{inc}}$ and $\mathrm{LC}_{\mathrm{dec}}$. In $\mathrm{LC}_{\mathrm{inc}}$, after the onset of the second step, oxyHb/Mb also began to decrease with a time delay of about $30 \mathrm{~s}$. The value of $\mathrm{oxyHb} / \mathrm{Mb}$ recorded at the 6th min was significantly lower than that recorded at the $3 \mathrm{rd} \min$ (Table 2). In $\mathrm{LC}_{\mathrm{dec}}$, after the onset of the second step, oxyHb/Mb increased gradually with time. However, the value of $\mathrm{xxyHb} / \mathrm{Mb}$ recorded at the 6th min was not significantly different from that recorded at the $3 \mathrm{rd} \min$ (Table 2). Compared to the value at the $3 \mathrm{rd}$ min of $\mathrm{LC}_{\mathrm{inc}}$, the value of oxyHb/Mb recorded at the 6 th min of $\mathrm{LC}_{\mathrm{dec}}$ was significantly lower despite the fact that the exercise intensities were the same (Table 2).

Figures $1 \mathrm{C}$ and 1D show average changes in $\dot{\mathrm{VE}}_{\text {hyper }}$ in $\mathrm{LC}_{\mathrm{inc}}$ and $\mathrm{LC}_{\mathrm{dec}}$, respectively. $\dot{\mathrm{VE}}_{\mathrm{hyper}}$ began to increase about $45 \mathrm{~s}$ after the onset of exercise in both $\mathrm{LC}_{\mathrm{inc}}$ and $\mathrm{LC}_{\mathrm{dec}}$. In $\mathrm{LC}_{\mathrm{inc}}, \dot{\mathrm{VE}}_{\text {hyper }}$ increased more after the onset of the second step. The value of $\dot{\mathrm{VE}}_{\text {hyper }}$ recorded at the 6th min was significantly higher than that recorded at the 3rd min (Table 2). In $\mathrm{LC}_{\mathrm{dec}}$, after the onset of the second step, $\dot{\mathrm{VE}}_{\text {hyper }}$ decreased gradually with time. However, the value of $\dot{\mathrm{VE}}_{\text {hyper }}$ recorded at the 6 th $\mathrm{min}$ 

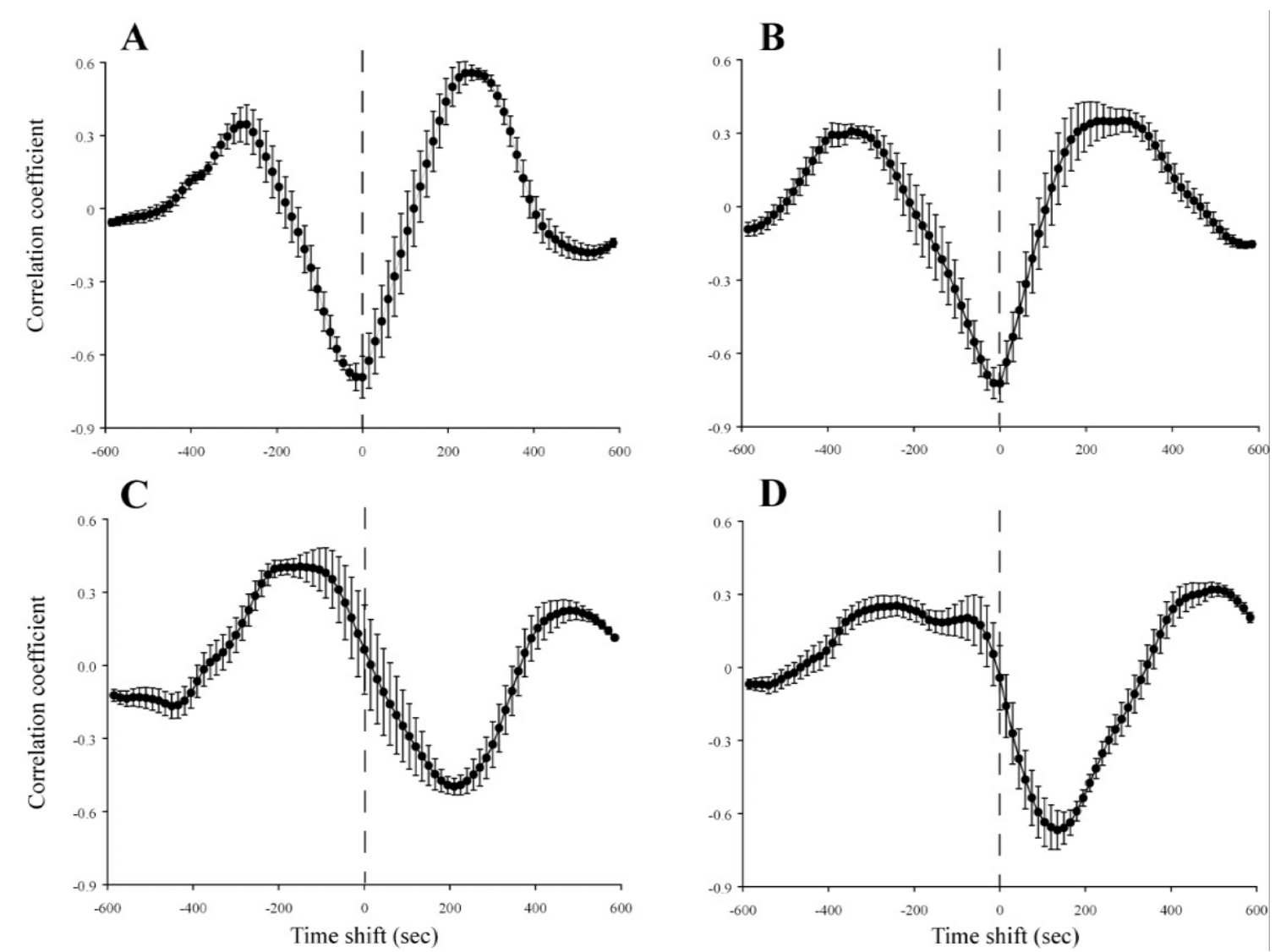

Fig. 2. Cross-correlation function (CCF) averaged for 7 subjects. A and B: CCF between oxygenated hemoglobin/myoglobin concentration in inactive biceps brachii muscle and amount of hyperventilation during two-step incremental and decremental leg cycling, respectively. C and D: CCF between oxygenated hemoglobin/myoglobin concentration in inactive biceps brachii muscle and predicted arterial $\mathrm{CO}_{2}$ pressure during two-step incremental and decremental leg cycling, respectively. Values are means \pm S.E.M.

was not significantly different from that recorded at the 3rd min (Table 2). Compared to the value at the 3rd min of $\mathrm{LC}_{\mathrm{inc}}$, the value of $\dot{\mathrm{VE}}_{\text {hyper }}$ recorded at the 6 th min of $\mathrm{LC}_{\mathrm{dec}}$ was significantly higher despite the fact that the exercise intensities were the same (Table 2).

Figures $1 \mathrm{E}$ and $1 \mathrm{~F}$ show average changes in $\mathrm{PaCO}_{2 \text { pre }}$ in $\mathrm{LC}_{\mathrm{inc}}$ and $\mathrm{LC}_{\mathrm{dec}}$, respectively. In contrast to

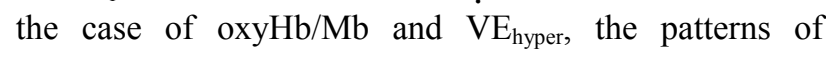
changes in $\mathrm{PaCO}_{2 \text { pre }}$ were similar in $\mathrm{LC}_{\text {inc }}$ and $\mathrm{LC}_{\mathrm{dec}}$. Briefly, $\mathrm{PaCO}_{2 \text { pre }}$ began to increase from the onset of exercise up to about the 1 st min of exercise. Thereafter, $\mathrm{PaCO}_{2 \text { pre }}$ decreased gradually until the end of exercise.

Table 2 shows the values of $\left[\mathrm{La}^{-}\right]$. In both $\mathrm{LC}_{\text {inc }}$ and $\mathrm{LC}_{\mathrm{dec}}$, the value of $\left[\mathrm{La}^{-}\right]$recorded at the 6 th min were significantly higher than those recorded at the 3rd min. Compared to the value at the $3 \mathrm{rd} \min$ of $\mathrm{LC}_{\mathrm{inc}}$, the value of $\left[\mathrm{La}^{-}\right]$recorded at the 6 th $\min$ of $\mathrm{LC}_{\mathrm{dec}}$ was significantly higher despite the fact that the exercise intensities were the same.

Figures. 2A and 2B show CCF between oxyHb/Mb and $\dot{\mathrm{VE}}_{\text {hyper }}$ in each two-step exercise test. The data are averages for seven subjects. In both $\mathrm{LC}_{\text {inc }}$ and $\mathrm{LC}_{\text {dec }}$, the $\mathrm{CCF}$ between oxyHb/Mb and $\mathrm{VE}_{\text {hyper }}$ showed a clear negative peak at the time shift of zero. The ranges of the time shift in seven subjects were between -60 and $30 \mathrm{~s}$ in $\mathrm{LC}_{\text {inc }}$ and between -90 and $30 \mathrm{~s}$ in $\mathrm{LC}_{\mathrm{dec}}$. Two subjects showed a negative peak at the time shift of zero in both $\mathrm{LC}_{\mathrm{inc}}$ and $\mathrm{LC}_{\mathrm{dec}}$. All peaks were statistically significant.

Figures 2C and 2D show $\mathrm{CCF}$ between oxyHb/Mb and $\mathrm{PaCO}_{2 \text { pre }}$ in each two-step exercise test. In both $\mathrm{LC}_{\mathrm{inc}}$ and $\mathrm{LC}_{\mathrm{dec}}$, no positive peak was observed near the time shift of zero.

\section{Discussion}

The main finding from this study is that the decrease in oxyHb/Mb in inactive biceps muscle is closely coupled with the increase in $\dot{\mathrm{VE}}_{\text {hyper }}$ but not with the decrease in $\mathrm{PaCO}_{2 \text { pre }}$ during leg cycling. Since $\mathrm{PaCO}_{2 \text { pre }}$ was used as an estimate of actual arterial $\mathrm{CO}_{2}$ pressure, it might be desirable to detect a possible 
difference between changes in oxyHb/Mb and $\mathrm{PaCO}_{2 \text { pre }}$ for determination of the difference between changes in oxyHb/Mb and actual $\mathrm{PaCO}_{2}$. Indeed, we obtained such an evidence: changes in $\mathrm{PaCO}_{2 \text { pre }}$ in $\mathrm{LC}_{\mathrm{inc}}$ and $\mathrm{LC}_{\mathrm{dec}}$ were very similar, whereas changes in oxyHb/Mb were completely different in the two exercise modes. Thus, we can safely state that change in oxyHb/Mb in inactive muscle is dissociated from that in actual $\mathrm{PaCO}_{2}$.

$\mathrm{The} \mathrm{oxyHb} / \mathrm{Mb}$ in inactive muscle began to decrease $30 \mathrm{~s}$ after the onset of exercise in both $\mathrm{LC}_{\mathrm{inc}}$ and $\mathrm{LC}_{\mathrm{dec}}$. A similar result was found in our previous study (Ogata et al. 2002) in which we showed that a decrease in oxygenation in inactive vastus lateralis muscle during arm cranking started more than 1 min after the onset of exercise. We attributed the decrease in oxygenation to the decrease in blood flow. In the present study, in $\mathrm{LC}_{\text {inc }}$, the magnitude of decrease in oxyHb/Mb became larger after the onset of the second step at a higher intensity. Taylor et al. (1992) observed that the magnitude of decrease in blood flow in the inactive forearm during leg cycling became larger with the increase in exercise intensity. Thus, a decrease in oxygen supply secondary to blood flow reduction caused the decrease in oxyHb/Mb in inactive muscle in the present study.

Sheel et al. (2002) reported that inactive leg blood flow at rest was reduced when the fatiguing inspiratory muscle work was loaded via voluntary increase in inspiratory effort against resistance. Sheel et al. (2002) also suggested that the sympathetic vasoconstriction was responsible for the decrease in the inactive leg blood flow during the inspiratory work because St Croix et al. (2000) found that the sympathetic nerve activity was increased by the same inspiratory muscle work. Thus, one might expect that the relationship between changes in oxyHb/Mb in inactive muscle and $\dot{\mathrm{VE}}_{\text {hyper }}$ becomes manifested because fatiguing respiratory muscle work associated with hyperventilation causes a decrease in blood flow in inactive arm muscle. However, fatigue of the diaphragm occurs during whole body endurance exercise in excess of $85 \%$ of maximal oxygen uptake (Johnson et al. 1993). This exercise intensity is above exercise intensity at which the decrease in oxyHb/Mb was observed in the present study (76\% $\mathrm{VO}_{2 \text { peak }}$ in the first step of $\mathrm{LC}_{\text {inc }}$ ).

Although we have no direct evidence for the association of the decrease in $0 x y \mathrm{Hb} / \mathrm{Mb}$ with the increase in $\dot{\mathrm{VE}}_{\text {hyper, }}$ we can propose the following working hypothesis. In the present study, the level of $\left[\mathrm{La}^{-}\right]$during the second step of $\mathrm{LC}_{\mathrm{dec}}$ was larger than that during the first step of $\mathrm{LC}_{\mathrm{inc}}$ despite the fact that work loads were the same. This larger increase in $\left[\mathrm{La}^{-}\right]$was accompanied by a larger decrease in oxyHb/Mb. In our previous study (Ogata et al. 2002), it was demonstrated that heavy arm cranking reduced oxygenation in inactive vastus lateralis muscle, whereas moderate arm cranking had no effect on oxygenation in inactive muscle. In addition, the decrease in inactive muscle oxygenation during heavy arm cranking started with a time delay of more than $1 \mathrm{~min}$. These results suggest the decrease in oxygenation in inactive muscle is coupled with accumulation of metabolites. The accumulation of metabolites results in metabolic acidosis. The acidosis is known to cause hyperventilation via autonomic reflexes evoked by stimulation on muscle metaboreceptors (Oelberg et al. 1998, Systrom et al. 2001) or carotid bodies (Wasserman et al. 1975). Thus, the decrease in inactive muscle oxygenation might be related to hyperventilation during exercise.

In our previous study (Ogata et al. 2004), we examined the kinetics of oxygenation in inactive forearm muscle during ramp leg cycling and could not find an apparent decrease in inactive muscle oxygenation from the VT at which hyperventilation occurs. In that study, we used ramp leg cycling at an increasing rate of 10 watts $\cdot \min ^{-1}$ in power output. According to the results obtained by Scheuermann and Kowalchuk (1998), the rate of increase in $\dot{\mathrm{VE}}_{\text {hyper }}$ per minute is lower during slow ramp exercise $\left(8\right.$ watts $\left.\cdot \min ^{-1}\right)$ than during fast ramp exercise $\left(65 \mathrm{watts} \cdot \mathrm{min}^{-1}\right)$. Thus, the decrease in inactive muscle oxygenation from the VT might be obscured during slow ramp exercise.

An increase in muscle oxygen consumption has been shown to be involved in a decrease of muscle oxygenation (Hamaoka et al. 1996). In the present study, however, the subjects were asked to keep their arms resting as much as possible on a table adjusted just below the height of heart level throughout the rest and exercise periods. Thus, the effect of an increase in muscle oxygen consumption on decrease in oxyHb/Mb would have been minimal.

In conclusion, the magnitude of decrease in oxygen supply to inactive muscle is closely coupled to the magnitude of increase in the amount of hyperventilation during exercise. This association may arise because accumulated metabolites have an effect concurrently on both oxygen supply to inactive muscle and hyperventilation. 


\section{References}

GRASSI B, POGLIAGHI S, RAMPICHINI S, QUARESIMA V, FERRARI M, MARCONI C, CERRETELLI P: Muscle oxygenation and pulmonary gas exchange kinetics during cycling exercise on-transitions in humans. J Appl Physiol 95: 149-158, 2003.

GROTE J, ZIMMER K, SCHUBERT R: Effects of severe arterial hypocapnia on regional blood flow regulation, tissue $\mathrm{PO}_{2}$ and metabolism in the brain cortex of cats. Pflügers Arch 391: 195-199, 1981.

GUSTAFSSON U, SJOBERG F, LEWIS DH, THORBORG P: The effect of hypocapnia on skeletal muscle microcirculatory blood flow, oxygenation and pH. Int J Microcirc Clin Exp 12: 131-141, 1993.

HAMAOKA T, IWANE H, SHIMOMITSU T, KATSUMURA T, MURASE N, NISHIO S, OSADA T, KUROSAWA Y, CHANCE B: Noninvasive measures of oxidative metabolism on working human muscles by near-infrared spectroscopy. J Appl Physiol 81: 1410-1417, 1996.

HAMPSON NB, PIANTADOSI CA: Near-infrared optical responses in feline brain and skeletal muscle tissues during respiratory acid-base imbalance. Brain Res 519: 249-254, 1990.

HIGUCHI H, HAMAOKA T, SAKO T, NISHIO S, KIME R, MURAKAMI M, KATSUMURA T: Oxygenation in vastus lateralis and lateral head of gastrocnemius during treadmill walking and running in humans. Eur J Appl Physiol 87: 343-349, 2002.

JOHNSON BD, BABCOCK MA, SUMAN OE, DEMPSEY JA: Exercise-induced diaphragmatic fatigue in healthy humans. J Physiol Lond 460: 385-405, 1993.

JONES NL, ROBERTSON DG, KANE JW: Difference between end-tidal and arterial $\mathrm{PCO}_{2}$ in exercise. J Appl Physiol 47: 954-960, 1979.

KOYAL SN, WHIPP BJ, HUNTSMAN D, BRAY GA, WASSERMAN K: Ventilatory responses to the metabolic acidosis of treadmill and cycle ergometry. J Appl Physiol 40: 864-867, 1976.

MANCINI DM, BOLINGER L, LI H, KENDRICK K, CHANCE B, WILSON J R: Validation of near-infrared spectroscopy in humans. J Appl Physiol 77: 2740-2747, 1994.

OELBERG DA, EVANS AB, HROVAT MI, PAPPAGIANOPOULOS PP, PATZ S, SYSTROM DM: Skeletal muscle chemoreflex and pHi in exercise ventilatory control. J Appl Physiol 84: 676-682, 1998.

OGATA H, YUNOKI T, YANO T: Effect of arm cranking on NIRS-determined blood volume and oxygenation of human inactive and exercising vastus lateralis muscle. Eur J Appl Physiol 86: 191-195, 2002.

OGATA H, REYIHAN A, YANO T: Kinetics of oxygenation in inactive forearm muscle during ramp leg cycling. J Physiol Anthropol Appl Human Sci 23: 7-17, 2004.

OSHIMA Y, MIYAMOTO T, TANAKA S, WADAZUMI T, KURIHARA N, FUJIMOTO S: Relationship between isocapnic buffering and maximal aerobic capacity in athletes. Eur J Appl Physiol 76: 409-414, 1997.

SCHEUERMANN BW, KOWALCHUK LM: Attenuated respiratory compensation during rapidly incremented ramp exercise. Respir Physiol 114: 227-238, 1998.

SHEEL AW, DERCHAK PA, PEGELOW DF, DEMPSEY JA: Threshold effects of respiratory muscle work on limb vascular resistance. Am J Physiol Heart Circ Physiol 282: H1732-H1738, 2002.

ST CROIX CM, MORGAN BJ, WETTER TJ, DEMPSEY JA: Fatiguing inspiratory muscle work causes reflex sympathetic activation in humans. J Physiol (Lond) 529: 493-504, 2000.

SYSTROM DM, HROVAT M, OELBERG D, KAZEMI H: Skeletal muscle chemoreflex in exercise ventilatory control. Adv Exp Med Biol 499: 343-348, 2001.

TAKANO N: Respiratory compensation point during incremental exercise as related to hypoxic ventilatory chemosensitivity and lactate increase in man. Jpn J Physiol 50: 449-455, 2000.

TAYLOR JA, HAND GA, JOHNSON DG, SEALS DR: Augmented forearm vasoconstriction during dynamic exercise in healthy older men. Circulation 86: 1789-1799, 1992.

TRAN TK, SAILASUTA N, KREUTZER U, HURD R, CHUNG Y, MOLE P, KUNO S, JUE T: Comparative analysis of NMR and NIRS measurements of intracellular $\mathrm{PO}_{2}$ in human skeletal muscle. Am J Physiol 276: R1682R1690, 1999. 
WASSERMAN K, WHIPP BJ, KOYAL SN, CLEARY MG: Effect of carotid body resection on ventilatory and acidbase control during exercise. J Appl Physiol 39: 354-358, 1975.

YANO T, HORIUCHI M, YUNOKI T, MATSUURA R, OGATA H: Relationship between maximal oxygen uptake and oxygenation level in inactive muscle at exhaustion in incremental exercise in humans. Physiol Res 54: $679-685,2005$.

\section{Reprint requests}

Hisayoshi Ogata, Motor Dysfunction Division, Research Institute of National Rehabilitation Center for Persons with Disabilities, 4-1 Namiki, Tokorozawa City, Saitama Pref., 359-8555 Japan. Fax: +814-2995-3132. E-mail: hisaoga@rehab.go.jp 